\title{
Сорбция ионов меди активированным углём марки БАУ-А
}

\author{
Линников О.Д., Родина И.В., Бакланова И.В., Сунцов А.Ю. \\ ФГБУН Институт химии твёрдого тела УрО РАН, Екатеринбург \\ Поступила в редакцию 19.03.2018 г.
}

DOI: https://doi.org/10.17308/sorpchrom.2018.18/563

Показана возможность использования активированного угля марки БАУ-А в целях очистки загрязненных растворов от ионов двухвалентной меди. Установлено, что сорбция ионов данного металла протекает по механизму физической адсорбции, описываемой уравнением Ленгмюра. Определены параметры этого уравнения при разных значениях рН модельного раствора.

Сопоставление ИК и КР спектров БАУ-А и другого угольного сорбента МИУ-С показало, что различия в их сорбционных свойствах по отношению к ионам меди во многом обусловлены отличиями в свойствах их поверхностей, а также структуре.

Ключевые слова: сорбция, активированный уголь, очистка воды, ионы меди(II), адсорбция, уравнение Ленгмюра.

\section{Sorption of ions $\mathrm{Cu}(\mathrm{II})$ by activated carbon BAU-A}

\author{
Linnikov O.D., Rodina I.V., Baklanova I.V., Suntsov A.Yu. \\ Institute of Solid State Chemistry, Ural Branch of the RAS, Ekaterinburg
}

The sorption properties of activated carbon BAU-A in the relation of copper ions were studied. The study was carried out using a model solution of sulfate of copper(II) containing additionally $400 \mathrm{mg} / \mathrm{l}$ of sodium sulfate. It was shown that activated carbon BAU-A may remove copper ions from polluted waters due to their physical adsorption on the surface of BAU-A, and the sorption process is well described by the Langmuir equation. The parameters of this equation were determined at different $\mathrm{pH}$ of the model solution. The capacity of an adsorption monolayer of BAU-A increases when $\mathrm{pH}$ of the solution grows from 4 to 6.7 (the ranges of $\mathrm{pH}<4$ and $\mathrm{pH}>6.7$ have not been investigated), and the sorption equilibrium constant on the contrary decreases. So, at $\mathrm{pH}=4$ the adsorptive capacity of the monolayer of the BAU-A for ions of copper(II) is $0.911 \mathrm{mg} / \mathrm{g}$ (or $0.00092 \mathrm{mg} / \mathrm{m}^{2}$ ), and the constant of the adsorptive balance is equal to 0.963 $\mathrm{dm}^{3} / \mathrm{mg}$. At $\mathrm{pH}=5$ it was found $1.573 \mathrm{mg} / \mathrm{g}$ (or $0.00160 \mathrm{mg} / \mathrm{m}^{2}$ ), and $1.197 \mathrm{dm}^{3} / \mathrm{mg}$, respectively. At $\mathrm{pH}=6-$ $2.517 \mathrm{mg} / \mathrm{g}$ (or $0.00256 \mathrm{mg} / \mathrm{m}^{2}$ ), and $0.788 \mathrm{dm}^{3} / \mathrm{mg}$. At $\mathrm{pH}=6.7-7.163 \mathrm{mg} / \mathrm{g}$ (or $0.00727 \mathrm{mg} / \mathrm{m}^{2}$ ), and 0.394 $\mathrm{dm}^{3} / \mathrm{mg}$.

Comparison of IR and Raman spectra of BAU-A and other carbon sorbent MIU-C showed that the differences in their sorption properties with respect to copper ions are due to differences in the properties of their surfaces, as well as to their structure. So, IR and Raman spectres showed that in the BAU-A carbon is in an amorphous state, and in IR spectrum of the MIU-C bands of absorption of water, hydroxyl groups $\mathrm{OH}$ and bonds of $\mathrm{C}-\mathrm{H}$ are found that demonstrates presence at this sorbent of alcohols.

Keywords: sorption, cleaning of water, ions $\mathrm{Cu}(\mathrm{II})$, adsorption, carbon sorbent, equation of Langmuir. 


\section{Введение}

Очистка сточных вод от ионов тяжёлых металлов является важной экологической задачей, которая осложняется тем, что применяемые в настоящее время осадительные и другие реагентные методы (например, с использованием известкового молока) не позволяют снизить концентрацию нежелательных примесей в загрязнённых растворах до нормативных значений. Особенно это касается вод, сбрасываемых в природные водоёмы, для которых установлены очень низкие ПДК по ионам тяжёлых металлов. Поэтому для достижения требуемой глубины очистки сточных вод необходимо применять их дополнительную финишную доочистку с использованием других способов. Одним из возможных вариантов такой доочистки является очистка загрязнённого раствора с использованием сорбентов, например, активированных углей.

Активированные угли различных марок давно используются для очистки газов, природных и сточных вод от загрязняющих примесей $[1,2]$. Наиболее часто их применяют для очистки воды от нефти и нежелательных органических соединений [1-4]. Кроме того, их также используют для удаления из загрязнённых вод катионов тяжёлых металлов [5-13].

В данной работе исследуются сорбционные свойства активированного угля БАУ-А по отношению к ионам меди. Этот сорбент уже давно применяется в промышленности для очистки загрязнённых вод от нефтепродуктов, фенолов и других органических примесей $[2-5,7,8]$. Однако, несмотря на это, детальные исследования механизма сорбции ионов тяжёлых металлов на БАУ-А до сих пор не проводились. В данной работе мы пытаемся частично заполнить этот пробел на примере сорбции ионов меди, которые были выбраны для исследования как ионы-загрязнители с самой низкой ПДК для водоёмов рыбохозяйственного назначения.

\section{Эксперимент}

Для исследований был использован технический активированный уголь БАУА (ГОСТ 6217-74). Эксперименты проводили на модельном водном растворе, имитирующем природные и сточные воды, который готовили путём растворения в дистиллированной воде сульфатов натрия и меди $\left(\mathrm{Na}_{2} \mathrm{SO}_{4}\right.$ и $\left.\mathrm{CuSO}_{4}\right)$. Концентрация

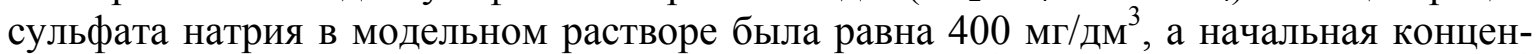
трация ионов меди менялась в опытах в от 3.816 мг/дм ${ }^{3}$ (при $\mathrm{pH}=6.7$ ) до $12.72 \mathrm{мг/дм^{3 }}$ (при $\mathrm{pH}=4)$. Объём модельного раствора в каждом эксперименте составлял $200 \mathrm{~cm}^{3}$, a концентрация сорбента в растворе варьировалась от 5 до 30 г/дм ${ }^{3}$. Все опыты проводили при комнатной температуре $\left(25 \pm 2^{\circ} \mathrm{C}\right)$ и непрерывном перемешивании магнитной мешалкой модельного раствора, в который добавляли сорбент. Затем через 30 минут выдержки сорбент отделяли от раствора фильтрованием через бумажный фильтр «синяя лента». Процесс фильтрации занимал 20-30 мин. Таким образом, общее время контакта раствора с сорбентом составляло 100-110 мин. Как показали предварительные опыты, этого времени было достаточно для достижения сорбционного равновесия в растворе. При этом было обнаружено, что при фильтрации растворов с низкой концентрацией меди происходит её частичная сорбция на используемом бумажном фильтре, и концентрация ионов меди в отфильтрованном растворе снижается, что искажает результаты анализа. Чтобы избежать этого (или, по крайней мере, снизить ошибку определения меди) при фильтрации отобранной пробы через бумажный фильтр «синяя лента» первую порцию раствора, объёмом около $100 \mathrm{~cm}^{3}$, отбрасывали и на анализ брали оставшуюся, отфильтрованную через этот же фильтр, 
часть отобранной пробы раствора. Концентрацию меди(II) в растворе определяли фотоколориметрическим методом с диэтилдитиокарбаматом натрия на фотоколориметре КФК-2 [14]. Погрешность определения составляла $2 \%$.

КР спектры снимали в диапазоне 50-4000 $\mathrm{cm}^{-1}$ при комнатной температуре на спектрометре RENISHAW-1000 ( $\lambda=532$ нм, P=25 мВт). ИК спектры поглощения порошкообразных образцов (таблетки в CsI) регистрировали на ИК Фурье спектрометpe VERTEX 80 (BRUKER) в диапазоне 4000-500 $\mathrm{cm}^{-1}$.

Большая часть экспериментов была выполнена при разных значениях $\mathrm{pH}$ раствора. Коррекция $\mathrm{pH}$ раствора до требуемого значения в этих опытах проводилась только после ввода БАУ-А в модельный раствор. Последующее поддержание в ходе опыта $\mathrm{pH}$ раствора на заданном уровне осуществлялось с помощью $\mathrm{pH}$-метра АНИ$\mathrm{OH} 4100$ и $0.1 \mathrm{~N}$ растворов серной кислоты и $\mathrm{NaOH}$. Отметим, что в этих и других подобных экспериментах электроды $\mathrm{pH}$-метра были постоянно погружены в модельный раствор с сорбентом в течение всего опыта. Удельная поверхность БАУ-А была определена методом БЭТ по адсорбции азота на установке Gemini VII 2390 V1.03 (USA).

\section{Обсуждение результатов}

Измерение удельной поверхности БАУ-А показало, что она равна $984.94 \mathrm{~m}^{2} /$ г. При этом поверхность пор составляет $674.6 \mathrm{~m}^{2} / \Gamma$. Это подтверждает литературные данные о том, что активированные угли обладают большой удельной поверхностью именно благодаря наличию пор.

При введении БАУ-А в раствор сульфата натрия в первые 20 мин с начала перемешивания образовавшейся суспензии наблюдалось довольно значительное повышение $\mathrm{pH}$ раствора (рис. 1, опыт 1) до значения $\mathrm{pH} \approx 9.5$, обусловленное, видимо, присутствием в БАУ-А малых количеств карбонатов кальция и магния, так как анализ раствора после выдержки в нём сорбента показал наличие в растворе бикарбо-

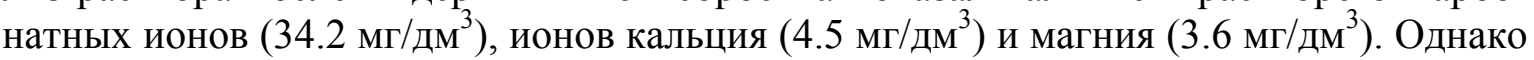
затем происходило постепенное понижение $\mathrm{pH}$, и примерно через 220 мин водородный показатель уменьшается до значении $\mathrm{pH} \approx 7.7$. Причина такого изменения щёлочности раствора не совсем понятна. Можно только предположить, что снижение $\mathrm{pH}$ раствора, возможно, обусловлено сорбцией анионов $\mathrm{OH}^{-}$на поверхности сорбента.
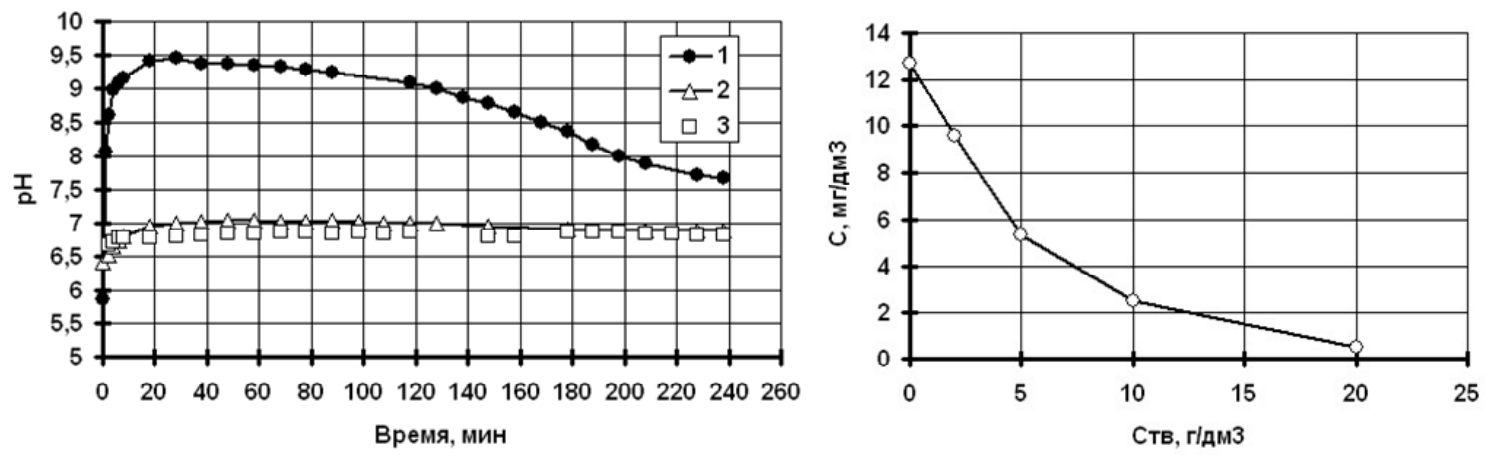

Рис. 1. Кинетика изменения $\mathrm{pH}$ раствора сульфата натрия (400 мг/дм $\left.{ }^{3}\right)$ при выдержке в нём сорбента БАУ-А при постоянном перемешивании суспензии магнитной мешалкой (концентрация сорбента в растворе $\mathrm{C}_{\mathrm{TB}}=2$ г/дм ${ }^{3}$ ): 1 - опыт 1 ;

Рис. 2. Влияние концентрации БАУ-А (Ств) на остаточное содержание (С) меди в модельном растворе при $\mathrm{pH}=5$ (начальная концентрация ионов меди в растворе $12.72 \mathrm{мг} /$ дм $\left.^{3}\right)$ 2 - опыт 2; 3 - опыт 3 
При повторной выдержке сорбента с опыта 1 в новом растворе сульфата натрия существенного подъёма $\mathrm{pH}$ раствора, такого, как в опыте 1 , не наблюдалось. Водородный показатель повышался незначительно (до $\mathrm{pH} \approx 7$ ) и стабилизировался на этом значении уже через 20 мин с начала перемешивания суспензии (рис. 1, опыт 2). При этом в растворе снижалось содержание бикарбонатных ионов $\left(24.4 \mathrm{мг} /\right.$ дм $\left.^{3}\right)$ и магния (2.4 мг/дм $\left.{ }^{3}\right)$, а кальций был обнаружен только в следовых количествах. Аналогичная картина наблюдалась и в опыте 3, когда сорбент с опыта 2 снова добавлялся в свежий раствор сульфата натрия (рис. 1, опыт 3). Как видно из рис. 1, экспериментальные точки опытов 2 и 3 легли практически на одну кривую. Химический анализ раствора после опыта 3 показал дальнейшее понижение в нём концентрации бикарбонатных ионов $\left(21.9 \mathrm{мг} /\right.$ дм $\left.^{3}\right)$ и магния $\left(1.4 \mathrm{мг} /\right.$ дм$\left.^{3}\right)$. Всё это подтверждает предположение о присутствии в БАУ-А небольших количеств карбонатных соединений кальция и магния, переход, которых в жидкую фазу и вызывает повышение рН раствора сульфата натрия.

В сорбционных экспериментах, чтобы избежать влияния изменения $\mathrm{pH}$ раствора при введении в него сорбента на процесс сорбции ионов меди, все опыты были проведены при постоянных значениях водородного показателя. Поддержание и коррекция рН раствора на постоянном значении в процессе каждого сорбционного эксперимента осуществлялась, как уже было сказано выше, с помощью 0.1 н растворов серной кислоты и $\mathrm{NaOH}$. Так, на рис. 2 показано изменение концентрации меди в модельном растворе при $\mathrm{pH}=5$ при введении в него БАУ-А. Как видно, увеличение концентрации сорбента в растворе приводит к существенному снижению концентрации ионов меди в нём. Аналогичные зависимости были получены и при других значениях $\mathrm{pH}$ раствора.

На рис. 3 приведены типичные изотермы сорбции ионов меди активированным углём БАУ-А в координатах линейной формы уравнения Ленгмюра для мономолекулярной адсорбции при проведении процесса сорбции при разных значениях рН модельного раствора:

$$
A=A_{\infty} \frac{K \cdot C}{1+K \cdot C}
$$

где $A$ - величина адсорбции, мг/г или мг $\mathrm{M}^{2} ; A_{\infty}$ - ёмкость адсорбционного монослоя сорбента, мг/г или мг $\mathrm{M}^{2} ; K-$ константа адсорбционного равновесия, дм ${ }^{3} / \mathrm{Mг}$.

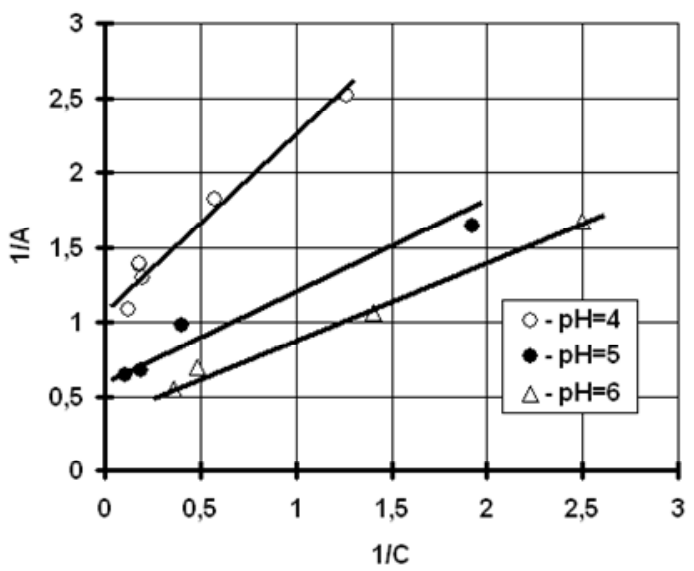

Рис. 3. Экспериментальные данные по сорбции ионов меди из модельного раствора активированным углём БАУ-А при разных значениях $\mathrm{pH}$ раствора в координатах линейной формы уравнения (1).

Как видно, все экспериментальные точки хорошо аппроксимируются прямыми. Это подтверждает справедливость уравнения Ленгмюра и указывает на то, что в 
данном случае протекает простая физическая адсорбция ионов меди на поверхности частиц БАУ-А.

Полученные данные позволили рассчитать параметры уравнения Ленгмюра (табл. 1). Отметим, что при $\mathrm{pH}<4$ адсорбция ионов меди БАУ-А нами не изучалась, а при $\mathrm{pH}>6.7$ получить достоверные результаты не удалось из-за большой экспериментальной ошибки определения концентрации ионов меди в растворе.

Таблица 1. Зависимость параметров уравнения (1) от $\mathrm{pH}$ раствора, в котором протекает процесс сорбции ионов меди $\left(\mathrm{R}_{\mathrm{c}}-\right.$ коэффициент корреляции)

\begin{tabular}{|c|c|c|c|c|}
\hline $\mathrm{pH}$ & $A_{\infty}, \mathrm{M \Gamma} / \Gamma$ & $A_{\infty}, \mathrm{M} \Gamma / \mathrm{M}^{2}$ & $K$, дм$^{3} / \mathrm{M \Gamma}$ & $\mathrm{R}_{\mathrm{c}}$ \\
\hline 4 & 0.9105 & 0.000924 & 0.9632 & 0.984 \\
\hline 5 & 1.5728 & 0.001597 & 1.1967 & 0.982 \\
\hline 6 & 2.5170 & 0.002556 & 0.7875 & 0.996 \\
\hline 6.7 & 7.1630 & 0.007273 & 0.3940 & 0.857 \\
\hline
\end{tabular}

Из данных табл. 1 видно, что ёмкость адсорбционного монослоя сорбента БАУ-А с повышением $\mathrm{pH}$ раствора резко возрастает. Одновременно с этим наблюдается снижение значения константы адсорбционного равновесия.

Представляет интерес сравнить найденные значения параметров уравнения Ленгмюра с аналогичными, опубликованными в литературе для других угольных сорбентов. Так, в работе [6] была изучена сорбция ионов меди кокосовым активированным углём марки NWC из модельных растворов хлорида меди. Обработка полученных данных показала, что лучше всего процесс сорбции может быть описан уравнением Ленгмюра, для которого были найдены следующие параметры: $A_{\infty}=21.88$ мг/г, $K=0.0081$ дм $^{3} /$ мг. К сожалению, в работе [6] не указано для какого значения $\mathrm{pH}$ модельного раствора были найдены эти величины и нет данных по удельной поверхности используемого активированного угля NWC. Поэтому корректное сравнение с нашими результатами провести невозможно. Видно, однако, что по адсорбционной ёмкости по отношению к ионам меди в размерности мг/г сорбент NWC почти на порядок превышает активированный уголь БАУ-А.

Сорбция ионов меди активированным углём БАУ-А была изучена в работе [7]. Условия проведения эксперимента, также как и в работе [6], не указаны. Полученные экспериментальные данные хорошо описывались уравнением Ленгмюра. Для ёмкости адсорбционного монослоя было найдено значение $3.3 \mathrm{мг} / г$, что с учётом удельной поверхности (740-840 $\left.\mathrm{m}^{2} / \Gamma\right)$ соответствует диапазону $0.0039-0.0045 \mathrm{Mг} / \mathrm{m}^{2}$, и близко к найденным нами значениям (см. табл. 1). Оценка из графической зависимости на рис. 1.2 [7] даёт величину $K=0.0003$ дм³ $^{3}$ мг, которая на два-три порядка ниже найденного нами значения.

В работе [9] при $\mathrm{pH}=4$ была изучена сорбция ионов меди на двух углеродных наноматериалах УНТ и УНЧ. Расчёт по данным, полученным в [9], показывает, что в обоих случаях процесс сорбции хорошо описывается уравнением Ленгмюра (коэффициенты корреляции 0.99 и 0.997 соответственно), и даёт следующие значения параметров для изотермы сорбции (для $20{ }^{\circ} \mathrm{C}$ ): УНТ (удельная поверхность 250-1800 $\left.\mathrm{M}^{2} / \Gamma\right)$ - $A_{\infty}=4.3706 \mathrm{мг} / \Gamma=0.0029-0.0175 \mathrm{мг} / \mathrm{m}^{2}, K=0.0474$ дм $^{3} / \mathrm{мг} ;$ УНЧ (удельная поверхность свыше $\left.1800 \mathrm{~m}^{2} / \Gamma\right)$ - $A_{\infty}=7.2886 \mathrm{мг} / \Gamma$ или менее $0.0041 \mathrm{мг} / \mathrm{m}^{2}, K=0.0288 \mathrm{дм}^{3} / \mathrm{Mг}$. Как видно, в обоих случаях рассчитанные значения ёмкости адсорбционного монослоя близки к нашим данным (см. табл. 1), а константы адсорбционного равновесия почти на порядок ниже.

Сорбция ионов меди углеродными сорбентами марки АД-05-2 и Сибунит была изучена в работе [10]. Пересчёт полученных там данных даёт следующие значе- 
ния для параметров уравнения Ленгмюра: АД-05-2 - $A_{\infty}=5144 \mathrm{мг} / \Gamma=8.04 \mathrm{мг} / \mathrm{m}^{2}$, $K=0.0084$ дм $^{3} /$ мг; Сибунит $-A_{\infty}=4699$ мг $/ \Gamma=10.44 \mathrm{мг} / \mathrm{m}^{2}, K=0.0112$ дм ${ }^{3} /$ мг. При сравнении с аналогичными параметрами для других углеродных сорбентов можно заметить, что в данном случае значения ёмкости адсорбционного монослоя чрезвычайно велики и поэтому нуждаются в проверке.

Значительный интерес представляет сопоставление полученных нами данных с сорбционными свойствами угольного сорбента МИУ-С, который был изучен нами ранее в тех же экспериментальных условиях и на таком же модельном растворе, что и БАУ-А [15]. Так, например, для сорбента МИУ-С при $\mathrm{pH}=6$ были найдены следующие значения констант уравнения Ленгмюра: $A_{\infty}=2.3004 \mathrm{M \Gamma} / \Gamma=0.1033 \mathrm{мг} / \mathrm{m}^{2}$, $K=0.4689$ дм $^{3} /$ мг. При $\mathrm{pH}=6.7$ эти параметры изменяются: $A_{\infty}=3.3069 \mathrm{мг} / \Gamma=0.1485$ $\mathrm{мг} / \mathrm{M}^{2}, K=0.8188$ дм $^{3} /$ мг [15].

Как видно, если в размерности мг/г адсорбционная ёмкость БАУ-А и МИУ-С имеют сопоставимы по величине, то в размерности мг/ ${ }^{2}$ они отличаются почти на порядок. При этом константы адсорбционного равновесия имеют также сопоставимые значения. Очевидно, имеющиеся различия во многом обусловлены разными сорбционными свойствами поверхностей сорбентов. Чтобы установить эти различия, были сняты ИК и КР спектры обоих сорбентов. Так, на рис. 4 приведены КР спектры угольного сорбента МИУ-С и активированного угля БАУ-А. При этом обнаруживаются значительные различия в их КР спектрах.

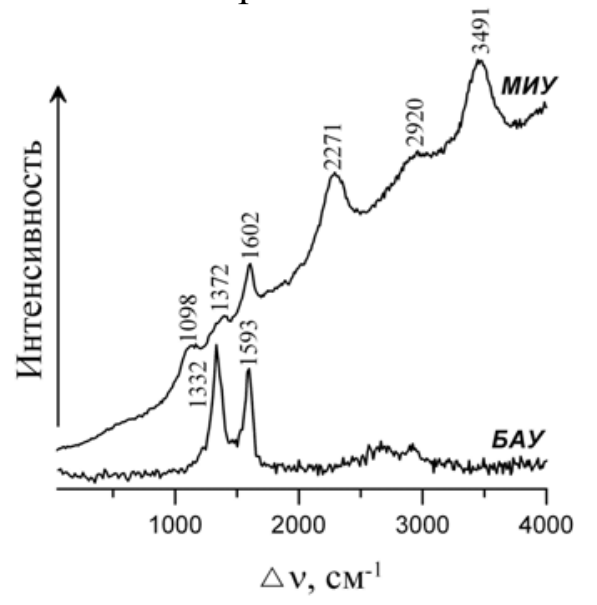

Рис. 4. КР спектры угольного сорбента МИУ-С и активированного угля БАУ-А

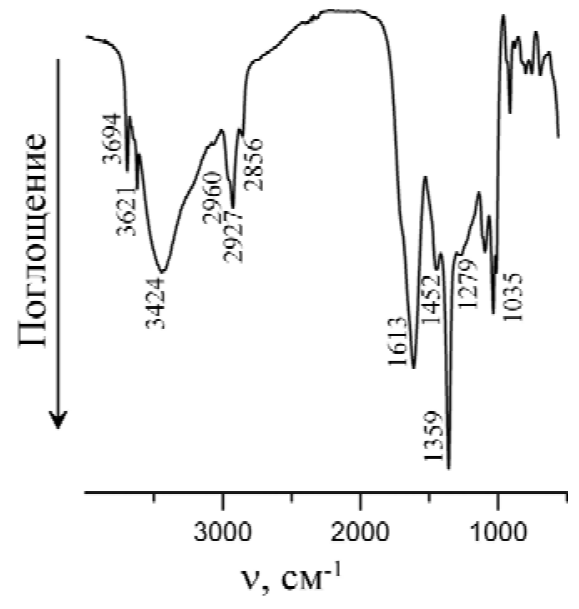

Рис. 5. ИК спектр угольного сорбента МИУ-С.

Из рис. 4 видно, что на КР спектре БАУ-А присутствуют две линии, характерные для аморфного углерода: D-линия при $1332 \mathrm{~cm}^{-1}$ и G-линия при $1593 \mathrm{~cm}^{-1}$. Положение и интенсивность G-линии при $1593 \mathrm{~cm}^{-1}$ позволяет определить степень графитизации углерода, поскольку она отвечает колебаниям атомов с $\mathrm{sp}^{2}$-типом гибридизации, находящихся в хорошо упорядоченных графитовых плоскостях. Линия при $1332 \mathrm{~cm}^{-1}$ обусловлена связями $\mathrm{C}-\mathrm{C} \mathrm{c} \mathrm{sp}{ }^{3}$-типом гибридизации, а также она ответственна за структурное разупорядочение и служит характеристикой степени дефектности фазы углерода, ее значительное уширение и высокая интенсивность свидетельствуют об аморфном состоянии углерода в исследуемых образцах сорбентов. Малые по интенсивности линии около 2600-3000 $\mathrm{cm}^{-1}$ являются обертонами линии D и G. Для МИУ-C наряду с линиями (D-линия при $1372 \mathrm{~cm}^{-1}$ и G-линия при $1602 \mathrm{~cm}^{-1}$ ) в спектре КР наблюдаются пики второго порядка, характерные для аморфного углерода (2271 и $\left.2920 \mathrm{~cm}^{-1}\right)$. Валентным колебаниям связей групп ОН отвечает линия при $3491 \mathrm{~cm}^{-1}$, а другая линия вблизи $1100 \mathrm{~cm}^{-1}$ - деформационным колебаниям гидроксила. 
ИК спектр угольного сорбента МИУ-С приведён на рис. 5. Для БАУ-А ИК спектр не удалось зарегистрировать, так как данный сорбент аттестован КР спектроскопией как аморфный углерод. Из рис. 5 видно, что на ИК спектре МИУ-С, также как и на КР спектре, наблюдаются характеристические полосы поглощения воды: валентные колебания при $3424 \mathrm{~cm}^{-1}$ и деформационные колебания при $1613 \mathrm{~cm}^{-1}$. Две узкие интенсивные полосы при 3694 и $3621 \mathrm{~cm}^{-1}$ соответствуют валентным колебаниям гидроксильных групп, а вблизи $1035 \mathrm{~cm}^{-1}$ расположены деформационные колебания связей ОН. Валентные асимметричные и симметричные колебания связей С-H характеризуются интенсивными узкими полосами при 2960, 2927 и $2856 \mathrm{~cm}^{-1}$, деформационные колебания - слабой полосой $1452 \mathrm{~cm}^{-1}$. В области частот веерных деформационных колебаний группы С-Н наблюдается узкая полоса малой интенсивности при $1279 \mathrm{~cm}^{-1}$. Полоса при $1359 \mathrm{~cm}^{-1}$ принадлежит асимметричным валентным колебаниям нитрат - иона (примесь в матрице иодида цезия). Наличие полос поглощения связей С-Н и ОН свидетельствует о присутствии в МИУ-С спиртов.

Таким образом, результаты КР и ИК исследований сорбентов БАУ-А и МИУС свидетельствуют о значительном различии в свойствах их поверхностей, а также структуре. Хотя оба сорбента практически на 100 \% состоят из углерода. Видимо, такие же отличия имеются и у других угольных сорбентов, что во многом и обуславливает их разные сорбционные свойства.

В работе [15] приведены также данные по параметрам уравнения Ленгмюра других угольных сорбентов, которые также свидетельствую о существенном различии их сорбционных свойств по отношению к ионам меди.

\section{Заключение}

Таким образом, выполненные исследования показали, что активированный уголь БАУ-А способен очищать загрязнённые растворы от ионов двухвалентной меди путём сорбции их на своей поверхности по механизму простой физической адсорбции, описываемой уравнением Ленгмюра. С повышением $\mathrm{pH}$ очищаемого раствора от 4 до 6.7 адсорбция ионов меди на поверхности МИУ-С4 возрастает (диапазоны $\mathrm{pH}<4$ и $\mathrm{pH}>6.7$ не были исследованы), что обусловлено ростом ёмкости монослоя БАУ-А. Однако при этом наблюдается уменьшение константы адсорбционного равновесия.

Сопоставление ИК и КР спектров БАУ-А и другого угольного сорбента МИУС показало, что различия в их сорбционных свойствах по отношению к ионам меди во многом обусловлены отличиями в свойствах их поверхностей, а также структуре.

Сорбент БАУ-А может быть рекомендован для очистки природных и сточных вод от ионов меди.

Работа выполнена в рамках государственного задания ФАНО России (плань НИР ИХТТ УрО РАН №№ АААА-А16-116122810209-5, АAАA-A16-116122810214-9, AAAA-A16-116122810217-0).

\section{Список литературы}

1. Мухин В.М., Курилкин А.А., Воропаева Н.Л., Лексюкова К.В. и др. // Сорбиионные и хроматографические проиессы. 2016. Т. 16. № 3. C. 346-353.
2. Зорина Е.И. // Сборник докладов III межотраслевой конференции «Вода в промышленности-2012». Москва. 2012. С. 122124. 
3. Смирнов А.Д. Сорбционная очистка воды. Л. Химия. 1982. 168 с.

4. Ряховский М.С. // Современные проблемы науки и образования. 2015. № 2 (часть 3 ). https://science-

education.ru/ru/article/view?id=23363

5. Дроздова Н.А., Юрьев Ю.Л. // Вестник

Казанского технологического университета. 2013. T. 16. C. 83-84. https://cyberleninka.ru/ article/n/izuchenie-sorbtsionnyh-svoystvaktivnogo-uglya-v-staticheskih-usloviyah

6. Смирнова Н.Н., Афонин Г.С. // Сорбиионные и хроматографические проиессы. 2017. T. 17. № 3. C. 422-428.

7. Гималаева А.Р., Валинурова Э.Р., Игдавлетова Д.К., Кудашева Ф.Х. // Сорбционные и хроматографические прочессы. 2011. Т. 11. № 3. C. 350-356.

8. Горбачёва М.П., Красавина Е.П., Мизина Л.В., Румер И.А. и др. // Химическая технология. 2017. Т. 18. № 6. С. 283-288.

9. Милютина А.Д., Колесников В.А., Колесников А.В. // Успехи в химии и химической технологии. 2016. Т. 30. № 1. С. 42-43.

\section{References}

1. Mukhin V.M., Kurilkin A.A., Voropaeva N.L., Leksyukova K.V. et al., Sorption and chromatographic processes, 2016, Vol. 16, No 2, pp. 346-353 (in Russian).

2. Zorin E.I. Proceeding of III interindustry conference "Water in industry-2012", Moscow, 2012, pp. 122-124 (in Russian).

3. Smirnov A.D. Sorption purification of water, L., Chemistry, 1982, 168 p. (in Russian).

4. Ryakhovsky M.S., Modern problems of science and education, 2015, No 2 (part 3) (in Russian). $\quad$ https://science-education.ru/ru/ article/view? id $=23363$

5. Drozdova N.A., Yur'ev Yu.L., Vestnik Kazanskogo tekhnologicheskogo universiteta, 2013, Vol. 16, pp. 83-84 (in Russian). https://cyberleninka.ru/article/n/izucheniesorbtsionnyh-svoystv-aktivnogo-uglya-vstaticheskih-usloviyah

6. Smirnova N. N., Afonin G. S., Sorbtsionnye $i$ khromatograficheskie protsessy, 2017, Vol. 17, No 3, pp. 422-428 (in Russian).

7. Himalaya A. R., Valinurova E. R., Igdavletova D. K., Kudasheva F. Kh., Sorbtsionnye $i$ khromatograficheskie protsessy, 2011, Vol. 11, No 3, pp. 350-356 (in Russian).
10. Сырых Ю.С. Автореф. дис.... канд. техн. наук. Иркутск, 2010. 29 с.

11. Филатова Е.Г., Анциферов Е.А., Помазкина О.И., Свитова А.О. // Сборник научных статей IX Международной научнотехнической конференции Наука, образование, производство в решении экологических проблем (Экология-2012), Уфа, 2012. Т. 2. С. 259-263.

12. Юстратов В.П., Соловьёва Ю.В. // Вестник Кузбасского государственного технического университета. 2006. № 1. С. 114-115.

13. Грищенко Э.С. Автореф. дис.... канд. техн. наук. Иркутск, 2005. 32 с.

14. Новиков Ю.В., Ласточкин К.О., Болдина 3.Н. Методы исследования качества воды водоёмов. Изд. 2-е, дополненное и переработанное. М. Медицина. 1990.400 с.

15. Линников О.Д., Родина И.В., Сунцов А.Ю. // Сорбиионные и хроматографические проиессы. 2017. № 5. С. 725-732.

8. Gorbacheva M.P., Krasavina E.P., Mizina L.V., Rumer I.A., Chemical technology, 2017, Vol. 18, No 6, pp. 283-288 (in Russian).

9. Milyutina A.D., Kolesnikov V. A., Kolesnikov A.V., Advances in chemistry and chemical technology, 2016, Vol. 30, No 1, pp. 42-43 (in Russian).

10. Syryh Yu.S. Thesis for a PhD degree, Irkutsk, 2010, 29 p (in Russian).

11. Filatova E.G., Antsiferov E.A., Pomazina O.I., Svitova A.O. Proceeding of IX International scientific and technical conference Science, edication, industry in solution of ecological problems (Ecology-2012), Ufa, 2012, Vol. 2, pp. 259-263 (in Russian).

12. Yustratov V.P., Solov'yova Yu.V., Bulletin of Kuzbass state technical university, 2006, No 1, pp. 114-115 (in Russian).

13. Grishchenko E.S. Thesis for a PhD degree, Irkutsk, 2005, 32 p (in Russian).

14. Novikov U.V., Lastochkin K.O., Boldina Z.N. Metody issledovania kachestva vody vodoemov, M., Meditsina, 1990, 400 p. (in Russian).

15. Linnikov O. D., Rodina I. V., Suntsov A. Yu., Sorbtsionnye i khromatograficheskie protsessy, 2017, No 5, pp. 725-732 (in Russian). 
Линников Олег Дмитриевич - Д.Х.Н., зав. лаб. Института химии твёрдого тела УрО РАН, Екатеринбург

Родина Ирина Васильевна - инженер 1-й категории Института химии твёрдого тела УрО РАН, Екатеринбург

Бакланова Инна Викторовна - к.х.н., научный сотрудник Института химии твёрдого тела УрО РАН, Екатеринбрг

Сунцов Алексей Юрьевич - к.Х.н., старший научный сотрудник Института химии твёрдого тела УрО РАН, Екатеринбрг
Linnikov Oleg D. - Head of Laboratory, PhD, Dr. Sci. (Physical Chemistry), Institute of Solid State Chemistry, Ural Branch of the Russian Academy of Sciences, Ekaterinburg, E-mail: linnikov@mail.ru

Rodina Irina V.- Engineer, Institute of Solid State Chemistry, Ural Branch of the Russian Academy of Sciences, Ekaterinburg

Baklanova Inna V. - Research associate, PhD, Institute of Solid State Chemistry, Ural Branch of the Russian Academy of Sciences, Ekaterinburg

Suntsov Alexey Yurievich - Senior Researcher, PhD, Institute of Solid State Chemistry, Ural Branch of the Russian Academy of Sciences, Ekaterinburg 